\title{
Women or Feminists? Assessing Women's Group Consciousness
}

\author{
Donna H. Henderson-King ${ }^{1}$ and Abigail J. Stewart
}

University of Michigan

Social psychological research often relies on measures of group identification in assessing levels of group consciousness. However, for women, the relationship between gender identification and group consciousness may not be a straightforward one. Questionnaire data were used to examine the relationships between measures of group identity and group evaluations with other attitudinal, phenomenological, and developmental measures of feminist consciousness. Research participants were 234 undergraduate women; the majority (75\%) were white and from middle-to upper-middle-class backgrounds. The results supported the hypothesis that use of the reference group "feminists," rather than the more general group "women," would be more strongly related to other dimensions of group consciousness in women.

Tajfel (1978a; 1982) specified two important components of the multidimensional concept of group consciousness, each of them involving group identification. The first component is an awareness of one's group membership, which is implied by self-identification as the member of a particular group. The second entails an evaluative stance towards one's group membership, one's group, or a related group. Research involving these particular components of group consciousness is prevalent in the social psychological literature (e.g., Abrams \& Hogg, 1990; Breakwell, 1992; Gurin, Miller \& Gurin, 1980). For some social groups, group identification may be so strongly tied to the broader concept of group consciousness that it serves as a useful indicator of an individual's level of group consciousness. However, for women, group identification, and the relationship between iden-

${ }^{1}$ To whom correspondence should be addressed at Women's Studies Program, 234 W. Engineering, University of Michigan, Ann Arbor, MI 48109. 
tification and group consciousness, may not be as straightforward as is the case for other groups. This study examines women's identification with two relevant groups, women and feminists, and the relationship that gender and feminist identification have with other dimensions of women's group consciousness.

\section{Gender Identification}

Past findings of relatively low levels of gender identification and group consciousness among women have been attributed in part to the high levels of contact and close relationships that women have with males (Gurin, Miller \& Gurin, 1980). Gurin et al. report that women's group identification and consciousness is lower than that of African-Americans and older people. Certainly the fact that women interact with males within the context of intimate and familiar relationships could help to explain why women might have lower levels of political consciousness than, for example, members of specific racial or ethnic groups. High levels of intimate engagement with members of another group may minimize the development of a group interest perspective or a critical analysis of intergroup relations.

It could be further argued that gender clearly functions as both a personal and social identity (see Taylor \& Dube, 1986, and Deaux, 1992, for discussions of personal and social identity), and that because gender is so central to their personal identity (i.e., their sense of themselves as individuals is so grounded in their conception of themselves as female), women are less likely to develop high levels of group consciousness. Given the social context within which both personal and social identities operate, it may be that because being female plays such an important role in women's personal identity, the tendency for gender to emerge as a strong basis for social identity (i.e., identification or a sense of connectedness with women as a social group, a sense of "we-ness") is diminished. The ideology of sexism is based not just on unequal relations between females and males and a devaluation of the feminine, but also on the assumption of heterosexuality (Rich, 1980), and on women's adoption of a male-centered perspective. Femininity, and the way in which girls and women are currently socialized into it, entails a turning towards men. For women to be feminine is not to recognize connections with other women; rather, it means to define themselves in terms of their relationships with men and, sometimes, to see other women as rivals for the attention of men. The institutionalization of heterosexuality means that women in general not only desire and have intimate relationships with men; it also means that they may downplay the value of relationships with women as they learn to make relationships with men of central importance. 
The impact of sexism and heterosexism will, of course, vary among individuals and different groups of women. For example, to the extent that lesbians are able to create lives outside a culture of heterosexuality, the weaker that impact will be. Nonetheless, making men the center of women's lives is done at the expense of their relationships with women and, therefore, at the expense of developing group identification and group consciousness. Consequently, we shouldn't expect generally high levels of gender identification among women, in the social identity sense of the term, nor should we expect to find a strong relationship between women's reported gender identification, either in terms of their self-identification as women or their evaluations of women, and feminist consciousness.

\section{Feminist Identification}

The rejection of the feminist label is common, even among women who clearly espouse feminist views (Griffin, 1989). This is particularly the case among young women, for whom the label has acquired very negative connotations (Kamen, 1991). In any sample of women, but especially in young women, we should expect to find relatively low levels of self-identification with feminists. That a woman does not identify herself as a feminist, though, does not necessarily mean she holds traditional attitudes about gender roles and gender relations, or that she is unaware of sexism.

The adoption of the feminist label, on the other hand, given negative stereotypes and portrayals of feminists, should be positively associated with other dimensions of feminist consciousness. To call oneself a feminist should indicate that a woman does, indeed, have feminist attitudes and an awareness of sexism. Thus, while we should not expect perfect correlations between women's self-identification as feminists and other measures of feminist consciousness, the political meaning of feminist identification should result in significant relationships with dimensions of feminist consciousness. By contrast, self-identification as women carries less political significance, and, therefore, should result in weaker relationships with other feminist consciousness measures. By the same logic, evaluations of feminists should be more strongly related to other dimensions of feminist consciousness than evaluations of women. 


\section{Hypotheses}

It was expected that women's feminist identification, but not their gender identification, would be strongly related to other measures of feminist consciousness.

It was also expected that women's group evaluations of feminists, but not of women, would be related to other measures of feminist consciousness.

\section{METHOD}

\section{Participants}

Participants were 234 female undergraduate students at the University of Michigan who had registered for a course in history, English or introductory women's studies. Participants had a mean of 2.4 years of undergraduate education, and the average age was 19.7 . The majority of participants $(75 \%)$ identified themselves as white; $7 \%$ were Asian; $5 \%$ were African-American; $3 \%$ were Hispanic; and 7\% indicated they were of other or mixed racial heritage. Although participants were not specifically asked about social class, most students attending the University of Michigan are from middle-to upper-middle-class backgrounds.

\section{Materials and Procedure}

Data for this study were from the first wave of a panel study of the development of group consciousness. Questionnaires were mailed to the homes of 506 undergraduate women. In return for personalized feedback, students were asked to complete the initial questionnaire as well as one which would be mailed at a later date. The response rate for this wave was $46 \%$.

\section{Measures of Group Identification and Evaluation}

In a revised version of a measure used in National Election Study surveys (Gurin, Miller \& Gurin, 1980), respondents were asked to consider a number of social groups, including women and feminists, and to write down the names of the groups to which they felt they belonged. Then, for each group they noted, respondents were asked to "indicate how much you identify with (or feel you are part of) that group" on a 
scale of 1 (not at all) to 5 (very much). Thus, as a result of this two-step process, the possible range of scores for Group Identity/Women and Group Identity/Feminists was 0 (the group was not specified as one to which they felt they belonged) to 5 (the group was specified and they identified very much with that group).

Feelings about Women and Feelings about Feminists were assessed using a feelings thermometer. Respondents were asked to indicate how they felt about several social groups, including women and feminists, using a scale from 0 (cool) to 100 (warm).

\section{Other Measures of Feminist Consciousness}

Several items from the NES were used to assess attitudinal dimensions of consciousness (Gurin et al., 1980). Power Discontent was assessed by asking respondents to indicate how much influence they believed a number of social groups have. Each group was rated on a five point scale ranging from -2 (far too little influence) to 2 (far too much influence). Groups of particular relevance for this study were women, men, and feminists. Data were recoded so that a high positive score meant a high level of discontent regarding the social power and influence attributed to each group.

Another set of NES items (Gurin et al., 1980) was used to measure women's rejection of the legitimacy of traditional gender roles and gender disparities (Rejection/Roles) and their rejection of the legitimacy of reasons used to support such disparities (Rejection/Reasons). Rejection/Roles was based on participants' level of agreement with two items (e.g., "Men and women ought to have an equal role in running business, industry and government"), and Rejection/Reasons was based on agreement with three items (e.g., "In general, men are more qualified for jobs that have great responsibility"). Possible scores ranged from 1 to 7 , and in both cases variables were recoded so that high scores indicated a stronger rejection of the legitimacy of roles or reasons.

In order to measure women's sense of common fate with other women (Gurin \& Townsend, 1986), respondents were asked whether they agreed with the statements: "Do you think that what happens to women generally in this country will have something to do with what happens in your life?" and "Do you think that the movement for women's rights has affected you personally?" Scores of 1 for no and 2 for yes were averaged across the two items, so that higher scores reflected a heightened Sense of Common Fate. 
A scale developed by the authors was used to assess Tajfel's (1978b) notion of the perception of instability in regard to gender relations. Using a seven point scale respondents indicated their level of agreement with two statements: "When it comes to sex roles and relations between males and females, things will always be pretty much the way they are now," and "In the future, relations between males and females could be quite different from the way they are now." The scale for the first item was reversed, so that a high average score across the two items reflected high levels of perceived Instability. The alpha coefficient for these items was .69.

A ten-item index developed by the authors was used to measure Sensitivity to Sexism (Bartky, 1975). ${ }^{2}$ The scale was designed to tap such phenomenological dimensions of consciousness as feelings of wariness concerning sexism and questioning one's perceptions of and reactions to apparently sexist events. Participants were asked how much they agreed or disagreed with statements such as "In certain situations I am tense because I'm expecting someone to say or do something sexist" and "Sometimes I'm not sure if what I'm seeing or hearing is sexist." An average score across this set of items was used, so that possible scores ranged from 1 to 7 with higher scores indicating higher levels of sensitivity. The Cronbach alpha coefficient for the scale was .85 .

We used a shortened version of Rickard's (1987; K. M. Rickard, personal communication, May 1990) Feminist Identity Scale (FIS) to measure four stages of feminist identity (Downing \& Roush, 1985). The first stage, Passive Acceptance, as the name suggests, is characterized by an acceptance of traditional gender relations and a dualistic view of the world in which males are perceived as superior. In the second stage, Revelation, consciousness undergoes a major shift as gender relations are reinterpreted, traditional roles are rejected, women are viewed as superior to men. During the stage of Embeddedness/Emanation, a woman tends to withdraw into a female subculture and focuses on relationships with other women; only during the latter part of this stage does she begin to interact once again with men, though in a cautious fashion. Finally, during Synthesis a woman begins to evaluate both men and women on the basis of individual characteristics rather than their group membership, and to realistically assess and adequately respond to sexism. Scores for each of the subscales could range from 1 to 5 , with higher scores indicating higher levels of the particular stage. Cronbach alpha coefficients for Passive Acceptance, Revelation, Embeddedness/Emanation and Synthesis were $.55, .80, .72$, and .59 respectively.

${ }^{2} \mathrm{~A}$ copy of the scale can be obtained from the first author. 
Table I. Means and Standard Deviations for Group Identification

\begin{tabular}{lrr}
\hline Measure & $M$ & \multicolumn{1}{c}{$S D$} \\
\hline Group Identity Women & 4.43 & 1.06 \\
Group Identity Feminists & 1.36 & 1.78 \\
Feelings about Women & 86.54 & 15.02 \\
Feelings about Feminists & 61.71 & 23.75 \\
\hline
\end{tabular}

\section{RESULTS}

Means and standard deviations for the Group Identity and Feelings variables are shown in Table I. Table II shows intercorrelations among the Group Identity and Feelings variables.

Pearson correlations pairing each of the Group Identity and Feelings variables with the other measures of feminist consciousness are shown in Table III. We hypothesized that identification with and evaluations of feminists, but not women, would be strongly related to other dimensions of group consciousness. As expected, Group Identity/Feminists was significantly related to all other measures of feminist consciousness. Group Identity/Women was related to fewer measures of feminist consciousness and the relationships were typically weaker than those involving Group Identity/Feminists.

There were five significant differences between the correlations for Group Identity/Feminists and Group Identity/Women. Group Identity/Feminists was more strongly related than Group Identity Women to Power Discontent/Feminists $(z=2.09, p<.05)$; Sensitivity to Sexism $(z=3.21$, $p<.01)$; Passive Acceptance $(z=3.89, p<.001)$, Revelation $(z=2.93$, $p<.01)$, and Embeddedness $(z=3.79, p<.001)$.

This same pattern of results was also evident for the Feelings variables. Feelings about Feminists was significantly related to all measures of feminist consciousness except Feelings about Men. Feelings about Women was related to fewer measures of consciousness, and the pattern of relationships was weaker. The only feminist consciousness measure which was more strongly related to Feelings about Women was Feelings about Men; there was no relationship between Feelings about Feminists and Feelings about Men.

Significant differences between the correlations for Feelings about Feminists and Feelings about Women were found for most of the measures of feminist consciousness. Feelings about Men was the only measure for which there was a stronger relationship with Feelings about Women than with Feelings about Feminists, $(z=-4.79, p<.001)$. For eight of the other measures, 
Table II. Pairwise Correlations among Group Identification Variables

\begin{tabular}{llcccc}
\hline & & 1 & 2 & 3 & 4 \\
\hline 1. & Group Identity Women & 1.00 & & & \\
2. Group Identity Feminists & $.29^{a}$ & 1.00 & & \\
3. & Feelings about Women & $.27^{a}$ & .09 & 1.00 & \\
4. & Feelings about Feminists & $.27^{a}$ & $.55^{a}$ & $.36^{a}$ & 1.00 \\
\hline
\end{tabular}

${ }^{a} p \leq .001$.

however, the relationship with Feelings about Feminists was stronger than that with Feelings about Women: Power Discontent/Women $(z=2.35, p<.05)$; Power Discontent/Feminists $(z=5.37, p<.001)$; Rejection Roles $(z=3.05$, $p<.01)$; Instability $(z=2.60, p<.01)$; Sensitivity to Sexism $(z=3.28$, $p<.01)$; Passive Acceptance $(z=3.28, p<.01)$; Revelation $(z=3.14$, $p<.01)$; and, Embeddedness/Emanation $(z=3.68, p<.001)$.

\section{DISCUSSION}

Findings from this study indicate that assessments of women's group consciousness benefit from a focus on the specific group "feminists" rather than the larger group "women." Although these findings are qualified by the nature of the present study's sample, and may differ for women in different age and racial or ethnic groups, for example, the present results suggest that these two group labels carry very different meanings for women. The correlations between measures related to feminists were stronger than those related to women. Thus, while it may be useful to directly ask members of some social groups about the group as a whole (e.g., groups based on age, race or ethnicity), with women it is particularly informative to ask about their feelings and/or identity concerning feminists, at least when the purpose is to assess group consciousness. Asking about gender identification may also be relevant, but it clearly holds a different meaning than does feminist identification.

Indeed, it is difficult to determine the meaning of high levels of gender identification, in terms of group consciousness. Note that for the women in this sample the average level of Group Identity/Women was 4.43 $(S D=1.1)$ out of a possible score of 5 . Only $5 \%$ of women in the sample indicated they were less than somewhat identified as women. The distribution for feminist identification was skewed in the opposite direction: $60 \%$ of the participants were not at all identified as feminists. The mean for Group Identity/Feminists was $1.36(S D=1.8)$. 
Table III. Pairwise Correlations for Group Identification Measures with Other Measures of Feminist Consciousness ${ }^{a}$

\begin{tabular}{lcccc}
\hline & $\begin{array}{c}\text { Group Id. } \\
\text { Women }\end{array}$ & $\begin{array}{c}\text { Group Id. } \\
\text { Feminists }\end{array}$ & $\begin{array}{c}\text { Feelings } \\
\text { Women }\end{array}$ & $\begin{array}{c}\text { Feelings } \\
\text { Feminists }\end{array}$ \\
\hline Power Discontent/Women & .14 & $.27^{c}$ & .10 & $.31^{c}$ \\
Power Dis./Feminists & $.20^{b}$ & $.39^{c}$ & .17 & $.61^{c}$ \\
Power Dis./Men & $-.18^{b}$ & $-.25^{c}$ & $-.23^{c}$ & $-.37^{c}$ \\
Rejection/Roles & .14 & $.23^{c}$ & $.16^{b}$ & $.42^{c}$ \\
Rejection & .14 & $.18^{b}$ & .14 & $.24 c^{c}$ \\
Instability & $.18^{b}$ & $.33^{c}$ & .12 & $.35^{c}$ \\
Sense of Common Fate & $.18^{b}$ & $.31^{c}$ & $.20^{b}$ & $.28^{c}$ \\
Feelings/Men & $.15^{b}$ & $-.21^{c}$ & $.43^{c}$ & .01 \\
Sensitivity to Sexism & $.23^{c}$ & $.49^{c}$ & .14 & $.42^{c}$ \\
Passive Acceptance & -.13 & $-.46^{c}$ & -.10 & $-.39^{c}$ \\
Revelation & $.16^{b}$ & $.41^{c}$ & $.17^{c}$ & $.44^{c}$ \\
Embeddedness/Emanation & $.19^{b}$ & $.50^{c}$ & .15 & $.46^{c}$ \\
Synthesis & $.21^{c}$ & $.27^{c}$ & $.18^{b}$ & $.23^{c}$ \\
\hline
\end{tabular}

${ }^{a}$ The minimum pairwise $n$ was 189 .

${ }^{b} p \leq .01$.

${ }^{c} p \leq .001$.

While we might expect women who score high on feminist identification to also be highly identified as women, we cannot make the reverse assumption that women who are highly identified as women will also be highly identified as feminist. In this sample, only $12 \%$ of those participants who were highly identified as women were also highly identified as feminist, while all of the participants who were highly identified as feminist were also highly identified as women. Condor (1989) maintains that the meaning and use of the social category "Woman" is variable. She argues the category is associated with different meanings for different interest groups and individuals, and that for feminists the meaning of the category "Woman" undergoes a transformation. Thus, women who span the continuum of feminist consciousness may strongly identify as women, but this identification may not reflect shared meanings and associations.

Although only one third of the respondents were at least somewhat identified as feminists and only $7 \%$ were strongly identified, we can be more confident of the meaning of this particular identification endorsement. As Griffin (1989) points out, given the negative associations with the feminist label, the adoption of a feminist identity may be resisted even when women hold clearly feminist views. To adopt this identity, however, is indicative that one does possess some level of feminist consciousness. 
In fact, when comparing women who were strongly identified as feminist and those who were strongly identified as women (but not feminist identified), there were significant differences on other measures of feminist consciousness. For example, despite a high level of gender identification, women who identified as women, but not feminists, were less likely to report a Sense of Common Fate with other women, $t(87)=-2.27, p<.05$. Women who were only identified as women were also higher on the stage of Passive Acceptance, $t(86)=6.40, p<.001$, indicating that, despite being gender identified, they were more likely to be unaware of sexism and to accept traditional gender roles. When examining dimensions of feminist consciousness, then, it is more useful to look to the more clearly political dimension of identification with feminists. It may be the case that in groups in which group consciousness is widespread, levels of general group identification carry predictive power, but that in groups in which consciousness is not widespread, the use of a referent group which is specifically political in nature (such as feminists) is a more useful measure of identification.

The results regarding group evaluations are even more striking than those for group identity. Most of the relationships with Feelings about Feminists were significantly different from those with Feelings about Women. Within the domain of group evaluations, then, it is very clear that evaluations of feminists, rather than women, will more closely capture the attitudinal, phenomenological, and developmental aspects of women's group consciousness.

It is interesting that Feelings about Women was not significantly related to the stage of Embeddedness/Emanation. This absence of a relationship is surprising since, from Downing \& Roush's (1985) perspective, Embeddedness is the stage at which women supposedly immerse themselves in women's groups and women's culture and focus on female relationships, so we would expect that feelings about women would be positively associated with this stage. However, it may be that women in the stage of Embeddedness are acutely aware of the differences among women, and that their reported feelings about women reflect both their rejection of women who do not share their views as well as their acceptance of women who do. It is also noteworthy that Feelings about Feminists is not at all related to Feelings about Men. Women who feel positively towards feminists are no more or less positive towards men as a group.

Social identity theory suggests that identification with and evaluations of one's group should be strongly related to other aspects of consciousness. This study provides evidence that, at least in the case of women, it is the politically specific group "feminists," rather than the general group "women," which seems to provide a more accurate assessment 
of group consciousness. Future research should address whether this finding holds across different groups of women. It may be the case that women's responses to these group labels are influenced by factors such as age, class, sexual orientation, or ethnicity. As we implied earlier, compared to straight women, lesbians' gender identification, in the social identity sense, may not be as negatively affected by the social context. To the extent that they make relationships with women central and do not compete with other women for men's attention, lesbian women may be more likely to identify with women as a social group and to evaluate women in relatively positive terms.

Though it might be expected that membership in more than one marginalized social group would detract from a woman's development of gender consciousness, multiple group membership may also enhance the ability to engage in the sort of critical analysis which lends itself to the development of group consciousness in general, thus facilitating the development of gender consciousness. Available evidence fails to support the detraction hypothesis; for example, while race/ethnicity may serve as a primary identity for people of color in the U.S., this is not at the expense of gender consciousness among women of color (e.g., Jones \& Jacklin, 1988; Robinson, 1987/1988). Adoption of the feminist label, however, is yet another issue. Women whose multiple group membership has marginalized their existence may eventually be more willing to adopt a label which is not generally in public favor. For example, the experience of living outside of social norms may make lesbian women less likely to resist the feminist label. On the other hand, factors such as ethnicity or class may have a negative effect on women's feminist identification. For instance, if the feminist movement has been perceived as a middle-class, white women's movement, women who are neither white nor middle-class might reject the feminist label despite holding feminist views. How the present findings might be complicated by attention to differences among women in sexual orientation, ethnicity, age or class, remains an important question.

\section{REFERENCES}

Abrams, D., \& Hogg, M. A. (1990). Social identity theory: Constructive and critical advances. New York: Springer-Verlag.

Bartky, S. L. (1975). Toward a phenomenology of feminist consciousness. Social Theory and Practice, 3, 425-439.

Breakwell, G. M. (1992). Social psychology of identity and the self-concept. London: Surrey University Press

Condor, S. (1989). Biting into the future: Social change and the social identity of women. In S. Skevington \& D. Baker (Eds.), The social identity of women. London: Sage. 
Deaux, K. (1992). Personalizing identity and socializing self. In G. M. Breakwell (Ed.), Social psychology of identity and the self-concept. London: Academic Press.

Downing, N. E., \& Roush, K. L. (1985). From passive acceptance to active commitment: A model of feminist identity development for women. The Counseling Psychologist, 13, 695-709.

Griffin, C. (1989). 'I'm not a women's libber but . . .' Feminism, consciousness and identity. In S. Skevington \& D. Baker (Eds.), The social identity of women. London: Sage.

Gurin, P., Miller, A. H., \& Gurin, G. (1980). Stratum identification and consciousness. Social Psychology Quarterly, 43, 30-47.

Gurin, P., \& Townsend, A. (1986). Properties of gender identity and their implications for gender consciousness. British Journal of Social Psychology, 25, 139-148.

Jones, G. P., \& Jacklin, C. N. (1988). Changes in sexist attitudes toward women during introductory women's and men's studies courses. Sex Roles, 18, 611-622.

Kamen, P. (1991). Feminist fatale. New York: Donald I. Fine.

Rich, A. (1980). Compulsory heterosexuality and lesbian existence. Signs, 5, 631-660.

Rickard, K. M. (1987, March). Feminist identity development: Scale development and initial validation studies. Paper presented at the Association for Women in Psychology, Denver, CO.

Robinson, D. M. (1988). The effect of multile group identity among black women on race consciousness. (Doctoral dissertation, University of Michigan, 1987.) Dissertation Abstracts International, 48, 2170.

Tajfel, H. (1978a). Differentiation between social groups: Studies in the social psychology of intergroup relations. London: Academic Press.

Tajfel, H. (1978b). The social psychology of minorities. (Report No. 38). London: Minority Rights Group.

Tajfel, H. (1982). Social psychology of intergroup relations. Annual Review of Psychology, 33, 1-39.

Taylor, D. M., \& Dube, L. (1986). Two faces of identity: The "I" and the "we." Journal of Social Issues, 42, 81-98. 